\title{
A fabricação digital como ferramenta de processo de projeto: conectando design e arquitetura
}

\author{
Digital fabrication as design process tool: connecting design and architecture
}

\author{
- Maria Candelária Ryberg \\ Universidade Federal de Santa Catarina \\ candelária.ryberg@gmail.com \\ - Maurício Storchi \\ Universidade Federal de Santa Catarina \\ mauriciostorchi@gmail.com
}

\author{
- Regiane Pupo \\ Universidade Federal de Santa Catarina \\ regipupo@gmail.com \\ - Ivan de Medeiros \\ Universidade Federal de Santa Catarina \\ ivanmedeiros75@gmail.com
}

\begin{abstract}
This paper describes a design experience about the insertion of Digital Fabrication, during design process, aiming the study and evaluation how this process can enrich, in a reciprocal way, the interdisciplinarity between Design and Architecture. Using a specific activity of an urban intervention, this article aims to elucidate that the permeability between areas as architecture and Design can bring innovative solutions and clarity during the process, besides the knowledge of different concepts.
\end{abstract}

Keywords: Digital Fabrication, Human Centered Design, Design Process

\section{Introdução}

As diversas formas de processo de projeto nas áreas de design e arquitetura, hoje, estão sendo repensadas em virtude da inserção das novas tecnologias para concepção, desenvolvimento e materialização. Cada vez mais, técnicas, ferramentas e métodos se completam, proporcionando ao designer e ao arquiteto um envolvimento literal durante todo o processo projetual. Com uma atividade pontual e específica de uma intervenção urbana, este artigo visa elucidar que a permeabilidade entre as áreas de Arquitetura e Design pode trazer soluções inovadoras, clareza durante o processo, além do conhecimento de diferentes experiências.

O processo de projeto arquitetônico é composto por etapas que possuem métodos e ferramentas específicos. Quanto maior a eficiência nessas etapas, maiores as contribuições para a melhoria dos projetos e, consequentemente, maior é a qualidade nas construções. A Fabricação Digital (FD), assim como as técnicas de parametrização de projeto, tem mostrado resultados inovadores e de qualidade nesse contexto, aliando eficiência, rapidez e precisão ao projeto arquitetônico. 0 potencial que estas novas tecnologias trazem à produção e ao gerenciamento de projetos amplia o processamento tridimensional, colaborando na compreensão espacial e no desenvolvimento de modelos rapidamente prototipados (CELANI, VAZ e PUPO, 2013).

No design, o processo e métodos de projeto, por vezes, são mais sistemáticos e concentram uma gama de técnicas e ferramentas que os tornam mais controlados e objetivos. Segundo Pazmino (2013), "Método é o caminho para se atingir uma finalidade, podendo ser entendido como um composto de várias técnicas". O método, supondo ser uma sistemática de trabalho, de organização e de rigor no desenvolvimento, conduz a soluções inovadoras, sendo que alguns destes são técnicas especificas para auxiliar o pensamento criativo (PAZMINO, 2013).

Ferramentas projetuais, como a parametrização, permitem estabelecer relações entre elementos ou grupo de elementos de um projeto a ser desenvolvido, atribuindo valores ou expressões numéricas a fim de organizar e controlar estas definições (CELANI, VAZ e PUPO, 2013). O que diferencia esta das ferramentas tradicionais de projeto, em que se inclui o sistema CAD, é a inter-relação dos elementos que compõem o mesmo. Uma vez estabelecidas as relações entre os elementos, o sistema composto por diversos parâmetros ganha autonomia, possibilitando explorar novas soluções que talvez não seriam atingidas com a utilização de sistemas convencionais. Como consequência, alterações dentro do projeto podem ser realizadas de maneira mais rápida, com a manipulação dos parâmetros, sem a necessidade de se recomeçar desde as fases iniciais. Ao mesmo tempo, a fabricação digital completa o entendimento, pois, de forma precisa e diversificada, tem a capacidade de materializar o projeto, causando maior compreensão espacial, formal e 
compositiva do que está sendo proposto.

Buscando uma integração entre práticas desenvolvidas na arquitetura e ferramentas utilizadas no design, o presente estudo analisa a inserção da Fabricação Digital e de sistemas paramétricos durante o processo de projeto de mobiliários urbanos, por meio de uma proposta de intervenção na Universidade Federal de Santa Catarina, em Florianópolis. Para tanto, elaborou-se um projeto de mobiliário para a Praça da Cidadania, coração da universidade, onde concentra-se o maior fluxo e número de usuários do campus. $\mathrm{O}$ estudo foi fundamentado em técnicas de Human Centered Design (HCD), em que o usuário é o principal ator do processo de projeto, influenciando desde as etapas de levantamento, concepção e análise, até a implementação da proposta (IDEO, 2009). Estas técnicas estão presentes em pesquisas de mercado e desenvolvimento de diversos produtos e serviços. $O$ projeto sustentou-se ao longo do processo nas possíveis técnicas de Fabricação Digital, com a elaboração de protótipos na impressora 3D, fabricação de modelos em escala menor com corte laser para estudo e análise dos meios de montagem, e, por último, a fabricação da proposta de mobiliário em escala 1:1.

\section{As Tecnologias e a Evolução do Processo de Projeto}

No processo de concepção de projetos de arquitetura, o projetista sempre terá um momento em que escolherá a forma de seu projeto. Este processo é influenciado por uma série de fatores, os quais foram, ao longo do tempo, sendo questionados e recebendo muitas respostas diferentes dependendo do contexto em que eram feitas. Podem-se citar como estes fatores, a função, o contexto ambiental e histórico em que ocorre o projeto, as características do local em que o projeto se insere, a cultura do local ou de seus usuários, o tempo de construção, as condições sociais, a moda, as restrições jurídicas e econômicas, etc. (VOORDT; VAN WEGEN, 2013).

À medida que há um aumento no número destes fatores, a relação entre a forma e a função passa a ter um caráter mais complexo. $\mathrm{O}$ ato de projetar é uma atividade humana, ou seja, as opiniões, preferências e a subjetividade dos envolvidos com o projeto acabam por influenciar tanto a forma como a função. Na maioria dos projetos, a forma nunca é totalmente livre. Um projeto atraente é apenas um dos fatores que levam uma arquitetura a ser considerada boa. Em suma, um bom projeto, que gere um bom resultado, é uma síntese bem sucedida da forma, da função, do custo e da tecnologia utilizada (VOORDT; VAN WEGEN, 2013).

Entretanto, a função exerce um peso considerável na escolha da forma. No fim do século XIX, com os ideais modernos, a funcionalidade passa a ser aceita como base na concepção de projetos, influenciando diversos setores além da arquitetura. A abordagem racional teve grande expansão, trazendo a produção em massa, a pré-fabricação, a padronização e a normalização como respostas a ideologia da época, buscando a velocidade de fabricação e economia de tempo e capital. A arquitetura, e boa parte da indústria de produção de bens, começaram a ser influenciados pelos processos de produção e pela facilidade de montagem.

$\mathrm{Na}$ arquitetura, o projeto é geralmente idealizado para cumprir uma determinada função e muitas vezes não se torna adequado a outras funções. Quando se trata de um projeto urbano, mais especificamente de uma intervenção urbana, a proposta projetada se insere no espaço público da cidade, sendo acessível por quase a totalidade da população. Ou seja, um projeto com esse caráter, deve ser dinâmico e versátil, atendendo as expectativas e necessidades de uma grande variedade de usuários. Além disso, o uso e os usuários mudam com o tempo, assim como a cidade se transforma na temporalidade. Portanto, muitos arquitetos e designers tentam produzir estruturas e produtos adequados a usos múltiplos, permitindo interpretações e intervenções individuais. Hertzberger (1963) escreveu:

"Para estar à altura das mudanças, as formas tem de ser construídas para permitir a miríade de interpretações. Têm de poder assumir vários significados e depois abandoná-los novamente sem prejudicar a sua identidade. Isso significa buscar formas primárias que, além de acetar um programa de necessidades, possam também libertar-se dele. A forma e as necessidades se inspiram uma na outra, A impossibilidade de criar um ambiente individual que se ajuste a todos torna necessário permitir interpretações individuais ao se projetar as coisas de modo a serem realmente capazes de interpretação."

Entretanto, podemos dizer que a frequência de projetos idealizados para usuários múltiplos e desconhecidos é cada vez maior. Isso nos leva a uma pasteurização de significados, formas e conceitos nos projetos. Vemos a produção em massa normatizar e padronizar produtos e observamos arquiteturas e projetos urbanos cada vez mais incógnitos que demonstram uma ausência de pertencimento ao local onde são concebidos, além de serem desprovidos de um estudo de uso e ocupação dos usuários à qual são destinados. Entretanto, projetistas encontram-se neste dilema: há um desejo pela originalidade do projeto, porém, ao introduzir as variáveis de custo e velocidade de materialização, os aspectos que dão personalidade ao produto final são deixados de lado em prol do orçamento e cronograma, optando-se muitas vezes por materiais de produção em massa, sem peculiaridades ou até mesmo sem relação com a proposta idealizada.

Muitas empresas e escritórios de arquitetura e design vêm, ao longo dos anos, tentando resolver este questão: Como projetar e concretizar as especificidades de um projeto, buscando não torná-lo padronizado, mas sim, manter uma originalidade, ao mesmo tempo em que há rapidez na materialização?

Mitchell (2001) observou que as consequências deste processo eram que os arquitetos desenhavam o que eles poderiam construir e construiam o que desenhavam. Este fato, mesmo com a inserção da arquitetura na era digital, não desapareceu completamente.

Isso demonstra a falta de conhecimento dos projetistas sobre construtibilidade, uma vez que estes ficam presos a 
desenvolver propostas com base nas experiências construtivas já consolidadas no mercado, não estudando, durante a etapa projetual, novas formas construtivas. Forms estas que poderiam ser compreendidas e testadas por softwares e tecnologias de modelagem, análise e materialização de modelos e projetos de maneira rápida e precisa. Esta falta de abertura às inovações tecnológicas se deve a certo receio de uma nova forma de pensar arquitetura, uma vez que estas tecnologias exigem uma nova lógica de projeto.

Para alguns designers, Fabricação Digital pode ser utilizada para a representação do desenho finalizado ou para estudar formas complexas por meio de artefatos físicos. Uma vantagem principal da FD é a sua capacidade para fabricar representações materiais de elevada qualidade para os desenhos complexos. O processo de design com FD também apoia o processo criativo de designers para produzir variações de um único artefato ou diversos artefatos em vários estágios de design (SASS e OXMAN, 2006). Do ponto de vista do processo de concepção e com a visão do design como processos contínuos e integrados de conceituação, materialização, e fabricação, oferece uma grande promessa para verdadeiramente uma nova definição de design, concluem os mesmos autores.

Por novas tecnologias entende-se conceber projetos paramétricos, ou seja, trabalhar com parâmetros em softwares de modelagem paramétrica permitindo uma melhora no ajuste de partes que afetam todo o sistema projetado. Por exemplo: quando um ponto em uma curva é reposicionado, toda a curva se realinha de forma autônoma. Isso garante maior facilidade de adaptação e mudança.

Esta nova maneira de projetar permite fornecer diversas possibilidades, principalmente para materialização de protótipos de maneira rápida e automatizada com a fabricação digital, garantindo otimização do tempo de análise do projeto, uma vez que este tempo, antes gasto no processo de construção dos protótipos, pode ser usado para a avaliação dos modelos.

Além disso, estas tecnologias abrem um grande leque de variáveis e problemáticas, antes negligenciadas nas etapas projetuais, passando agora a serem elucidadas na fase de elaboração, criação e desenvolvimento de propostas, garantindo maior precisão e compreensão do projeto desde os primeiros lançamentos de ideias, até o canteiro de obras.

Desta forma, este trabalho é uma tentativa experimental de avaliar a inserção de novas tecnologias, com ênfase na Fabricação Digital, durante o processo projetual, a fim de estudar e avaliar como este processo pode vir a enriquecer, de maneira recíproca, a interdisciplinaridade entre a área de design e arquitetura.

\section{Metodologia}

O presente estudo é parte de uma pesquisa de natureza exploratória e qualitativa, com abordagem multi-métodos que visam compreender a percepção e o comportamento dos usuários no ambiente, aliado à aplicação da fabricação digital no processo projetual. Os métodos aqui apresentados abordam desde o processo de análise da área de intervenção até a materialização da forma em escala 1:1 do projeto desenvolvido.

A partir da revisão crítica de literatura sobre a temática, foi traçada uma metodologia que aborda a interdisciplinaridade entre o design, arquitetura e tecnologia. Este processo dividiu-se em duas etapas: processo criativo e processo de modelagem/fabricação, os quais, em diversos momentos, se cruzaram, tornando o entendimento da forma e suas possíveis soluções mais precisos. Já desde as primeiras fases do projeto, a interpolação dos processos utilizados em design e em arquitetura pôde contribuir para a proposta.

A etapa de processo criativo consistiu na análise da área de estudo - realizada através de observações sistemáticas e aplicação de questionários com o publico alvo - e na geração de alternativas. A etapa de modelagem utilizou-se das tecnologias projetuais já citadas - Parametrização, Prototipagem e Fabricação Digital. Segue abaixo uma descrição de cada uma das etapas:
a) Revisão Crítica de literatura

A revisão crítica de literatura foi realizada com o objetivo de aprofundar-se em três temáticas:

- Compreender o HCD (Human Centered Design) e outros meios de inserir o usuário no processo projetual;

- Estudar novas tecnologias aplicadas ao design, como a Fabricação Digital e sistemas paramétricos, compreendendo seus benefícios, limitações e meios de aplicação;

- Compreender a utilização de equipamentos e mobiliários urbanos, estudando-se também referenciais já existentes. b) Processo criativo

Análise da área de intervenção

O diagnóstico da área de intervenção visou compreender a dinâmica das atividades e a interação dos usuários no espaço de estudo, com o objetivo de dar subsídios para o desenvolvimento da proposta projetual. Para isto, foi desenvolvido e aplicado um método de análise composto por: Observação-Questionário-Observação. Primeiramente, observaram-se os usuários em diferentes horários e períodos da semana, para ter uma visão geral das principais atividades e ações. Para discussão e análise dos dados coletados, foram utilizados desenhos, registros fotográficos e vídeos. Após este primeiro contato, foi elaborado um questionário com 15 perguntas de multiplaescolha, definidas com base nas informações observadas na primeira análise. Este questionário foi aplicado na própria praça com uma atmosfera de 30 estudantes, escolhidos aletoriamente, frenquentadores do local, buscando escolher pessoas em diferentes períodos do dia, para abranger maior variedade de público. Para análise e tabulação dos dados organizaram-se gráficos sobre cada questão, com a porcentagem que cada alternativa foi assinalada. A partir desta análise, realizou-se uma nova observação da área de intervenção, para confirmar os dados obtidos e verificiar possiveis considerações finais ou divergências. 
Mapa conceitual, painel semântico, brainstorming

Após as etapas de diagnóstico e iniciando o processo projetual, optou-se pela aplicação de diferentes métodos de design que estimulassem o processo criativo, a fim de criar mais consciência sobre as intenções de projeto. Primeiramente, elaborou-se um mapa conceitual com palavras-chaves referentes aos meios de apropriação dos usuários, facilitando a priorização de conceitos norteadores da proposta. A partir disto, elaborou-se um painel semântico com imagens que representariam cada conceito escolhido, tornando mais claro e visível tais intenções. Por último, foi realizado um brainstorming com todos os dados discutidos anteriormente, com croquis de propostas de intervenção e referências, buscando discutir em conjunto o design do mobiliário.

c) Processo de modelagem e fabricação

Capacitação do software

Para a etapa de modelagem e fabricação optou-se pela utilização do software Rihnoceros e do seu pluggin Grasshoper, permitindo um projeto parametrizado, de fácil prototipagem e fabricação 1:1. Como o contato da equipe com esta nova ferramenta ainda se dava em estágio muito inicial, houve uma capacitação de toda equipe envolvida para domínio do software, além da compreensão de técnnicas de materialização como impressoras 3D, cortadora a laser e CNC.

Modelagem e geração de alternativas

Após as primeiras definições de projeto, iniciou-se o processo de modelagem do mobiliário proposto, dando continuidade ao processo criativo de maneira mais prática. Os primeiros estudos foram realizados a partir de desenhos e maquetes manuais, característicos do processo tradicional de projeto em arquitetura. Posteriormente, as alternativas foram modeladas no software Rhinoceros com auxílio do pluggin Grasshoper, utilizando-se da impressora 3D e cortadora laser como ferramentas para testes a partir do estudo de protótipos.

Fabricação na escala 1.1

A partir da definição do projeto final de mobiliário, uma proposta foi fabricada na escala 1:1. Para isso, após a preparação do projeto escolhido e sua fabricaçao, utilizou-se uma fresadora $\mathrm{CNC}$.

Após sua fabricação, os equipamentos e/ou mobiliários foram inseridos na área de intervenção para apropriação pelos usuários. É nesta etapa que foi realizada uma nova análise comportamental, com o objetivo de testar e avaliar a proposta desenvolvida, além de observar qual a resposta do usuário perante o projeto. Para esta análise, é utilizado novamente o método Observação-QuestionárioObservação, assim como na primeira etapa do diagnóstico. Neste momento, avaliam-se os efeitos e resultados da inserção da diferenciada metodologia projetual, para compreender se a mesma respondeu efetivamente às necessidades dos usuários, percebidas na primeira etapa de diagnóstico.

\section{Desenvolvimento do Processo Projetual: Da Análise à Fabricação}

\section{Análise da área de intervenção}

A praça da Cidadania é considerada o coração da universidade, tanto pela sua posição estratégica quanto pelo papel que representa para os estudantes - um local comum a todos os centros, de convívio e passagem. A faixa etária dos usuários está entre jovens estudantes de 18 a 30 anos. Estes utilizam a praça sozinhos ou acompanhados durante o horário de intervalo ou pausas na rotina. É também muito utilizada como passagem, contando com importantes fluxos que conectam os centros da universidade.

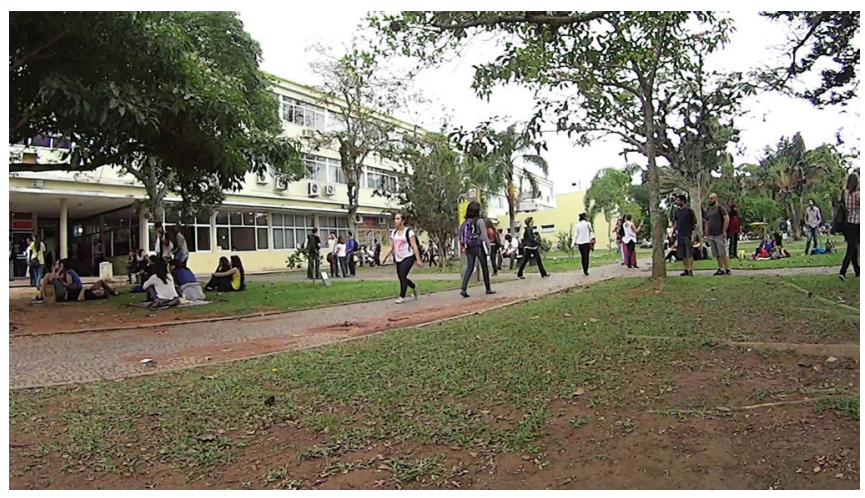

Figura 1: Foto da Praça da Cidadania - Universidade Federal de Santa Catarina. FONTE: Autores.

Por tratar-se de um local aberto, com conceitos de integração, convivência e cidadania, desenvolveram-se na praça intervenções de diferentes tipologias, sejam elas manifestações artísticas ou culturais. Estas são visualizadas pela quantidade de monumentos que se encontram no local, tornando a praça um local de intenso uso e apropriação por parte de estudantes e demais usuários. Ocorrem no local, ainda, eventos esporádicos, como festejos acadêmicos, sessões de cinema aberto, shows, festivais, apresentações artísticas, etc. Há ainda eventos periódicos, como a tradicional feira de alimentos orgânicos, artesanatos, lanches e demais amostras, que acontece todas as quartas-feiras, movimentando diversos usuários e promovendo pequenos comércios.

As entradas da praça apresentam um fluxo ininterrupto, que se eleva em horários específicos, como no início e fim das aulas e, principalmente, durante o horário do almoço, devido à proximidade do restaurante universitário. Quanto à permanência, há um maior número de usuários depois do almoço e durante a tarde, principalmente quando o clima está agradável. Nas quartas-feiras, devido a tradicional feirinha e as apresentações musicais que ali se desenvolvem, a praça apresenta ainda mais movimento, fazendo com que o gramado permaneça completamente ocupado por rodas de estar.

Percebe-se que hoje a praça apresenta mobiliário precário, contando com poucos bancos, lixeiras e postes de iluminação. 
Sua implantação parece estar jogada ao acaso, não criando relações com as edificações e com o desenho urbano da praça conformada em frente ao Centro de Comunicação e Expressão da UFSC. Entretanto, o pouco mobiliário presente é usado pelos estudantes, que buscam, ainda, outras formas de apropriar-se do espaço que não dependa de qualquer equipamento.

Características importantes em relação ao usuário e os meios de apropriação com o espaço, reveladas na pesquisa:

- proximidade com o solo: usuários preferem sentar no gramado ou nas raízes das árvores, escorando-se geralmente nos seus troncos.

- $\quad$ sombra: variável que determina o espaço de permanência - os usuários preferem as áreas sombreadas do que as áreas ao sol.

- Árvores/Vegetação: apresentam uma relação mais intensa com os usuários pois, além do sombreamento, delimitam um espaço, com maior proteção da visibilidade, permitindo o encosto.

- Liberdade: um dos maiores problemas dos mobiliários atuais é sua pouca versatilidade eliberdade de apropriação e locomoção. Eles encontram-se em lugares fixos com uma função bastante limitada.

\section{Processo criativo}

O desenvolvimento criativo da proposta ocorreu após plena consciência das atividades e usuários da área de intervenção, o que tornou o processo mais claro e objetivo. A elaboração de um mapa conceitual (Figura 1) buscou trazer as palavras mais fortes que se destacaram durante a observação da Praça da cidadania: Liberdade, Solo, Vegetação, Arvores, Sombreamento, Descanso, etc.

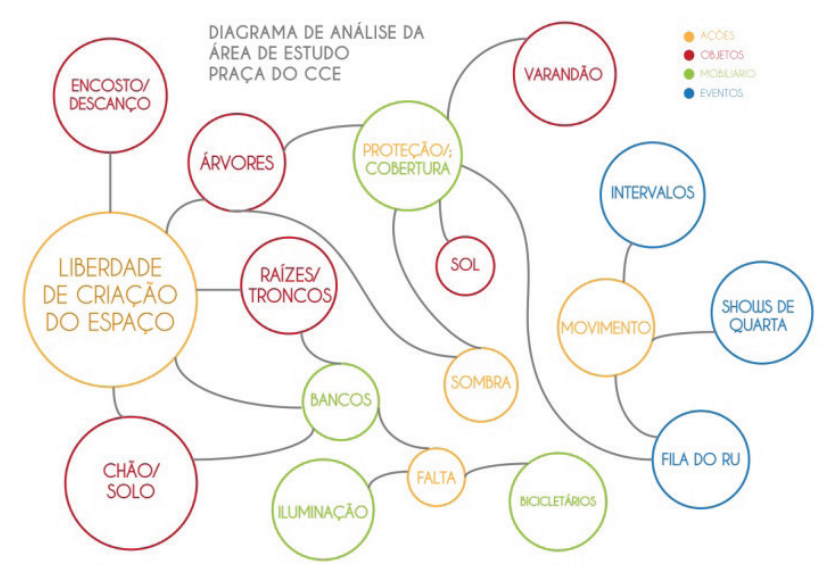

Figura 2: Mapa conceitual de análise da área de estudo. FONTE: Autoria própria.

A partir disso, com o objetivo de filtrar os conceitos mais relevantes e poder buscar aspectos que os correlacionassem para a materialização de um mobiliário, selecionaram-se imagens que representavam cada conceito. Estas imagens, que formam um painel semântico (Figura 2), não deveriam estar relacionadas necessariamente a mobiliários, mas a sensação que cada palavra do mapa conceitual transmite.

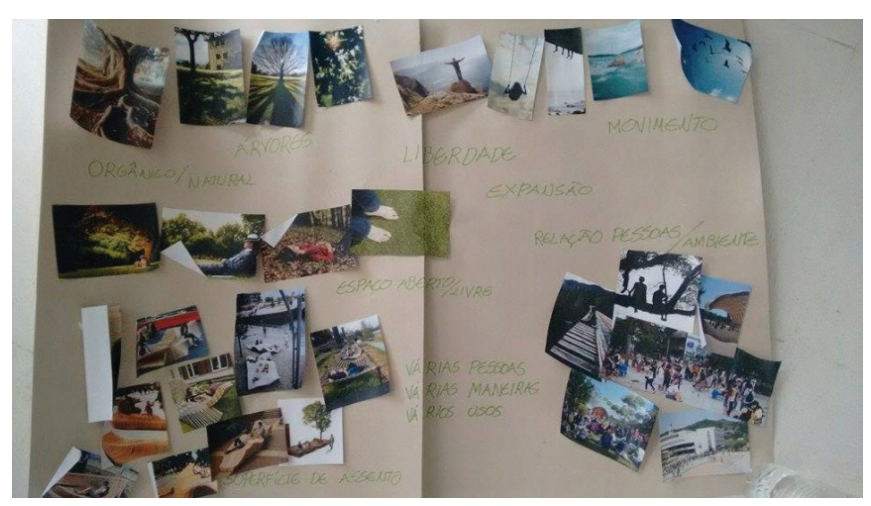

Figura 3: Painel semântico referente aos conceitos da área de intervenção. FONTE: Autoria própria.

Ao analisar todas as imagens juntas, percebe-se que a maior parte delas tem relação com a natureza e com um dinamismo fluido. Com isso, a proposta tende a um objeto orgânico, que se integre ao ambiente e não perca a sua forte relação com o solo. Tal proposta deve também permitir que os usuários tenham a escolha de onde e como se apropriar do mobiliário e do espaço, dando ênfase no conceito de liberdade.

Portanto, a proposta resultou em um mobiliário multifuncional. Trata-se de pequenos elementos, que se integram com a paisagem e servem de complemento para as funções já executadas pelos usuários junto às árvores. Estes elementos adaptam-se facilmente a encostos, assentos, mesas, ou outras funções na qual o usuário destinar. Estes elementos são leves, o que permite sua fácil alocação ou manejo, podendo criar centros de estar ou isolamento.

\section{Processo de modelagem e fabricação}

A modelagem das possíveis propostas foi inicialmente desenvolvida no software Rhinoceros. Quando adquirida a consciência do desenho do mobiliário, iniciou-se o processo paramétrico de projeto, através do pluggin Grasshopper.

O primeiro passo foi definir a área de implantação, representada no software por uma curva. Esta curva serviu de base para a elaboração do mobiliário, que teria formas orgânicas que acompanhariam o seu desenho. A partir desta curva, o mobiliário se forma por parâmetros pré-estabelecidos referentes às análises anteriores sobre a área de intervenção, e questões ergonômicas e de conforto, como altura do nível do solo, altura do encosto, altura do nível de assento. A figura 3 mostra o desenvolvimento do processo, com a utilização do software.

A partir da modelagem da primeira etapa do mobiliário, foram fabricados protótipos na impressora 3D (Figura 4). Nesta etapa do processo tornaram-se evidentes os erros de modelagem: áreas muito curvas, pouco espaço de acento, encosto insuficiente, etc. A cada ajuste ou alteração do mobiliário foram feitas novas impressões. Destaca-se a importância desta etapa pois muitos 
destes erros não são possíveis de analisar unicamente no computador. Além disso, a impressão de pequenos protótipos é uma tarefa ágil e prática, que permite o aperfeiçoamento do projeto e evita futuros erros de execução.

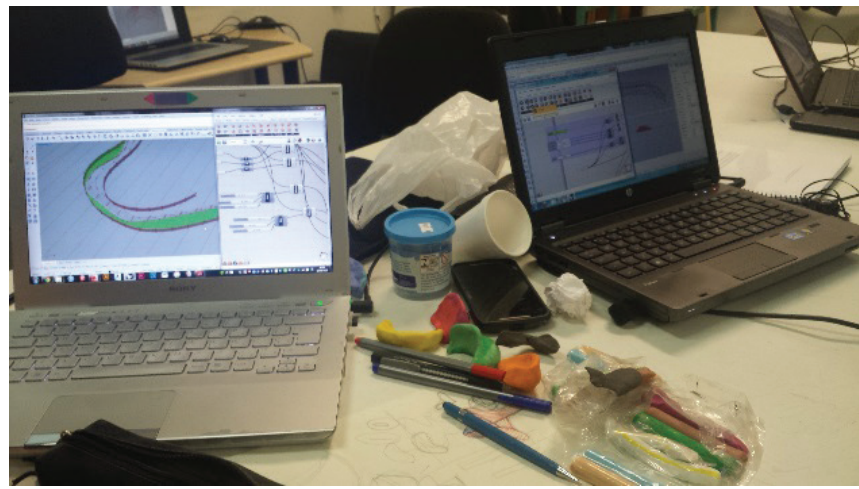

Figura 4: Processo de modelagem parametrizada utilizando o software Rhinoceros e o pluggin Grasshoper. FONTE: Autoria própria.

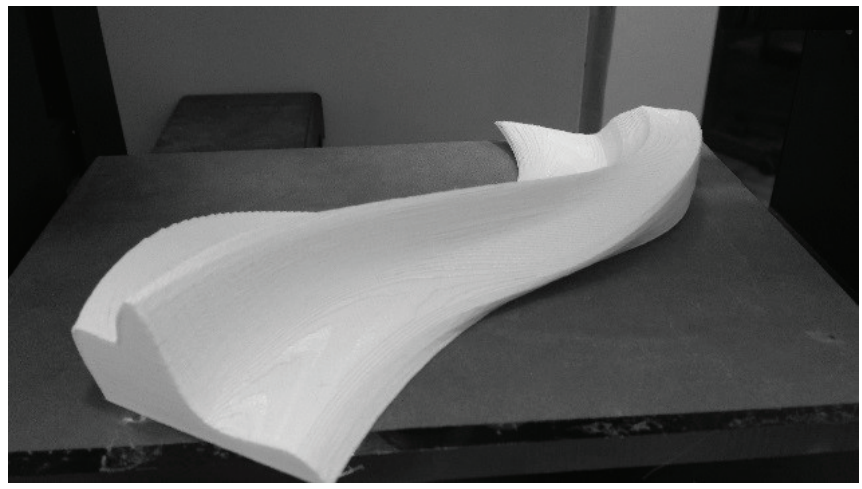

Figura 5: Protótipo do mobiliário impressos na impressora 3D FONTE: Autoria própria.

Depois de executados os ajustes na proposta do mobiliário, estudaram-se os seus meios de construtibilidade. Como a proposta de fabricação na escala 1:1 é utilizando a técnica interlocking com placas de MDF, o primeiro teste realizado foi para verificar a estrutura da peça, simulando o mobiliário na escala 1:5. Para tanto, foram necessários estudos da orientação dos eixos, dos afastamentos entre as placas e dos encaixes. Estes estudos foram realizados com a produção de cortes e construção de $1 / 3$ do comprimento total do modelo obtido, em menor escala, para verificação de encaixes e consistência do modelo.

A execução do interlocking e sua planificação foi realizada no software 123DMake, com a primeira tentativa de corte das peças em Papel Paraná, espessura 1mm, em cortadora laser. Nesta etapa encontraram-se dificuldades de montagem da peça, visto a irregularidade na espessura do material e nos encaixes justos. Portanto, foi necessário fazer um novo teste ainda na escala reduzida, com MDF e encaixes mais frouxos. Foi utilizado então o MDF de $3 \mathrm{~mm}$, ainda na cortadora a laser (Figura 5). Esta ferramenta mostrou-se também ágil, de fácil manuseio e de extrema importância para identificar falhas e evitar futuros problemas na fabricação 1:1.
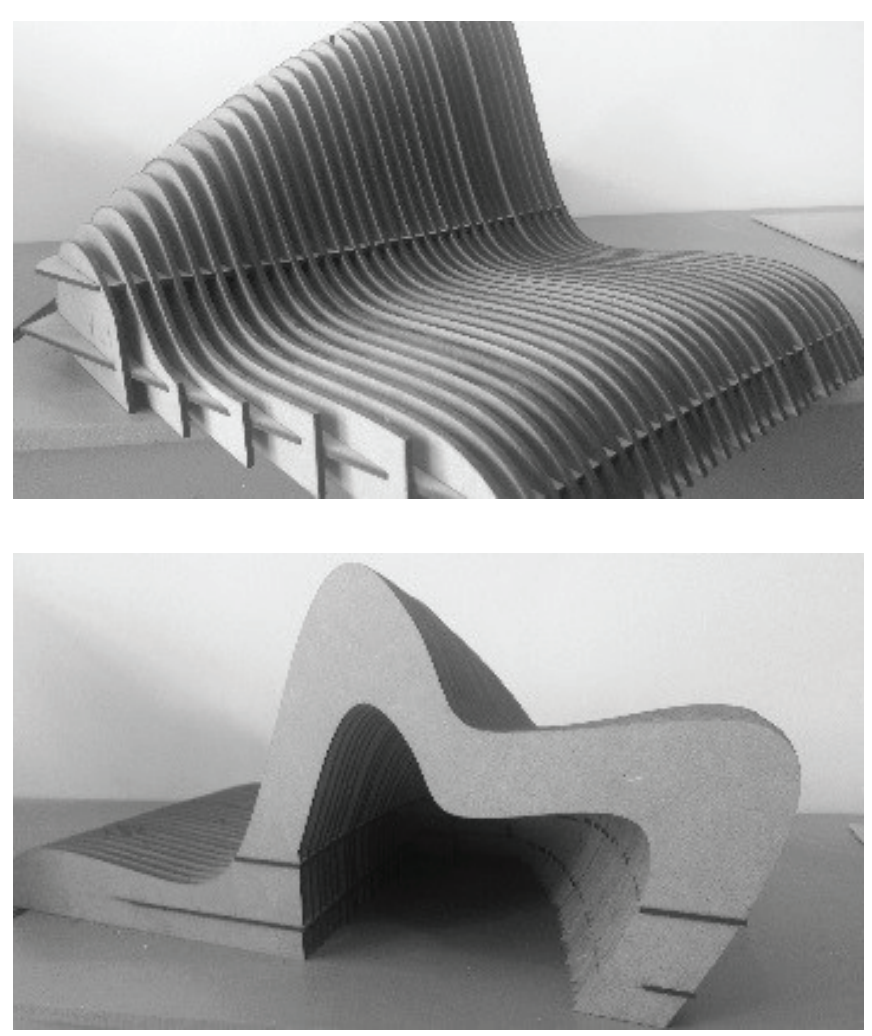

Figura 6 e 7: Cortes das peças para montagem do mobiliário em Interlocking, em escala reduzida. FONTE: Autoria própria.

Após realizados todos os testes necessários para o refinamento do projeto, foi realizado o corte na escala 1:1, em MDF 6mm, com a utilização de fresadora CNC. Ainda na produção de apenas $1 / 3$ do comprimento total da peça modelada, este processo foi mais demorado do que o esperado, visto as falhas encontradas na falta de interoperabilidade entre os softwares envolvidos para a produção do modelo em escala 1:1.

A primeira dificuldade foi na exportação dos desenhos entre o software 123DMake e o software de geração de percurso de usinagem, para posterior obtenção de g-Code, responsável pela leitura da CNC. Desencontros milimétricos nas formas obtidas impediam o reconhecimento do software da $\mathrm{CNC}$ para corte. $\mathrm{Na}$ tentativa de minimizar o problema, as peças foram reajustadas com a utilização do AutoCAD, o que tornou o processo mais lento do que o esperado.

Quando da finalização e publicação deste artigo, as peças do protótipo em escala 1:1 estavam em fase de corte e construção e, portanto, não puderam ser mostradas nesta etapa. Com 50\% dos cortes prontos (Figura 6) o uso da CNC para corte do material proposto (MDF $6 \mathrm{~mm}$ ), se mostrou eficiente quanto a rapidez e precisão nas formas encontradas. 


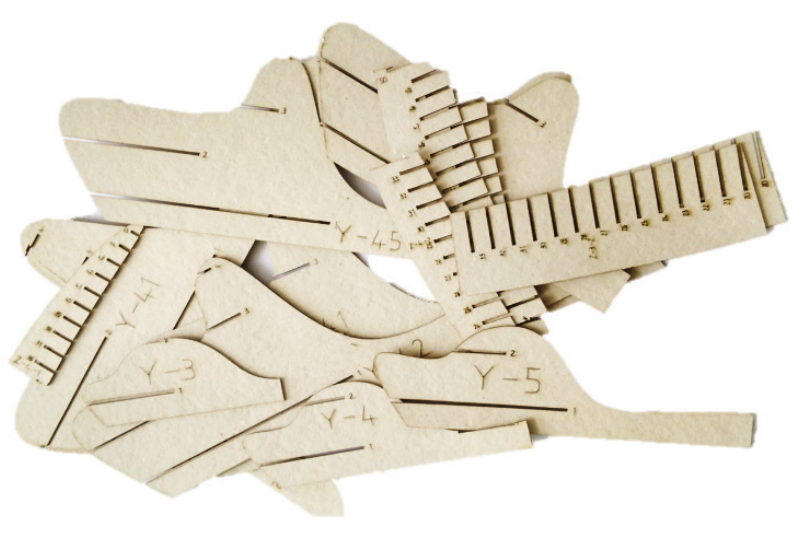

Figura 8: Cortes em CNC em escala 1:1 FONTE: Autoria própria.

\section{Análise das Ferramentas Fabricação}

A partir da experimentação de diferentes ferramentas de fabricação digital inseridas no processo de projeto, analisaramse os aspectos positivos e negativos que resultaram deste processo (Tabela1).

\begin{tabular}{|c|c|c|}
\hline & Pontos positivos & Pontos negativos \\
\hline $\begin{array}{l}\text { Modelagem } \\
\text { paramétrica }\end{array}$ & $\begin{array}{l}\text { Facilidade de futuras } \\
\text { replicações. }\end{array}$ & $\begin{array}{l}\text { Complexidade do } \\
\text { software; } \\
\text { Limitações do desenho; } \\
\text { Exigência de mais } \\
\text { tempo para a } \\
\text { modelagem. }\end{array}$ \\
\hline Impressão 3D & $\begin{array}{l}\text { Agilidade e facilidade } \\
\text { de execução; } \\
\text { Possibilidade de } \\
\text { corrigir erros do } \\
\text { projeto antes de sua } \\
\text { execução. }\end{array}$ & \\
\hline Corte a laser & $\begin{array}{l}\text { Agilidade e facilidade } \\
\text { de execução; } \\
\text { Possibilidade de } \\
\text { corrigir erros do } \\
\text { projeto antes de sua } \\
\text { execução. }\end{array}$ & \\
\hline Corte na CNC & $\begin{array}{l}\text { Agilidade e precisão } \\
\text { de corte. }\end{array}$ & $\begin{array}{l}\text { Complexidade do } \\
\text { software de usinagem; } \\
\text { Falta de } \\
\text { interoperabilidade } \\
\text { entre os softwares } \\
\text { envolvidos; } \\
\text { Necessidade de ajustar } \\
\text { manualmente todas as } \\
\text { peças; } \\
\text { Problemas técnicos } \\
\text { na máquina - } \\
\text { interrupções no } \\
\text { processo. }\end{array}$ \\
\hline
\end{tabular}

Tabela 1: Tabela síntese da análise das ferramentas de fabricação digital. FONTE: Autoria Própria.

\section{Considerações Finais}

A inserção da Fabricação Digital como ferramenta de projeto permite ao projetista pensar sobre diversas condicionantes que permeiam o processo projetual, principalmente no que se refere a aspectos construtivos. Quanto à fase de estudo e análise, a Fabricação Digital mostrou-se facilitadora para materialização de protótipos e estudos em escalas reais, o que possibilita o teste do projeto e torna seus problemas mais visíveis. Deste modo, o projetista adquire maior consciência das problemáticas, levando não só a um refinamento e qualificação do projeto, mas também evita futuros conflitos de execução.

A Parametrização do mobiliário mostrou-se essencial para a intenção de um projeto versátil e de diferentes aplicações. Uma vez definida a programação, a alteração da modelagem torna-se muito mais ágil, o que permite a replicação do mobiliário proposto para outras localidades, mantendo seus aspectos ergonômicos, alterando-se apenas os parâmetros referentes a implantação.

A experiência mostrou que as diversas técnicas de materialização utilizadas durante a pesquisa não inibem a produção criativa ou a limita de maneira rígida como os sistemas convencionais. Ao contrário, quando inserida no processo projetual, pode vir a fornecer diversas possibilidades, principalmente para materialização de protótipos de maneira rápida e automatizada, garantindo otimização do tempo de análise do projeto, uma vez que este tempo, antes gasto no processo de construção dos protótipos, pode ser usado para a avaliação do projeto.

A experiência com Fabricação Digital durante o processo projetual força o projetista a pensar desde o início sobre construtibilidade - o que eram apenas linhas no papel, passam a ser elementos reais com atributos e tolerâncias. Tais ferramentas permitem unir, também, diversas plataformas e abrem um leque maior de possibilidades para o projetista - desde desenvolvimento de geometrias complexas, até o controle de suas propriedades, além de análises de variáveis estruturais, de conforto ambiental e também estéticas.

\section{Referências}

Celani, G.; Vaz, C.; Pupo, R. (2013). Sistemas generativos de projeto: classificação e reflexão sob o ponto de vista da representação e dos meios de produção.

Revista Brasileira de Expressão Gráfica, São Paulo, v. 1, n. 1.

IDEO. (2009). Human-Centered Design: Kit de Ferramentas. 2. ed. Palo Alto, California: Ideo. Disponível em:<http://www. ideo.com/images/uploads/hcd_toolkit/HCD_

Portuguese.pdf>. Acesso em: 10 fev. 2015.

Krippendorff, K. (2000) .Propositions of Human-centeredness: A Philosophy for Design. In: Durling, D.; Friedman, K. (Eds.). Doctoral Education in Design: Foundations for the Future. Staffordshire (UK): Staffordshire University Press.

Voordt, THEO J. M. van der, WEGEN, Herman B. R. van Wegen. (2003). Arquitetura sob o olhar do usuário. São Paulo: 
Oficina de Textos

Mitchell, William J. (2001). "The Revenge of Place." In Proceedings, Space Syntax, 3rd International Symposium,
01.1-01.6. Atlanta: Georgia Institute of Technology.

Pazmino, A. V. (2013) Como se cria: 40 métodos para design de produtos. São Paulo: Blucher. 